\title{
Penanganan Sampah di Kota Pulang Pisau Kabupaten Pulang Pisau
}

\author{
Maretina Eka Sinta \\ Program Studi Teknik Sipil, Fakultas Teknik, Universitas Kristen Palangka Raya \\ *email:inamaretina@yahoo.com
}

\begin{abstract}
ABSTRAK. Sampah merupakan benda yang sudah tidak terpakai, baik berasal dari rumah tangga maupun pabrik sisa proses industri. Pengelolaan sampah merupakan suatu bidang yang berhubungan dengan pengaturan terhadap penimbunan, penyimpanan sementara, pengumpulan, pemindahan, pengangkutan dan pembuangan sampah dengan cara yang sesuai dengan prinsip-prinsip terbaik.penilitian ini bertujuan untuk mengetahui bagaimana jumlah volume sampah dan cara penanganan sampah. Penanganan masalah sampah adalah sampel penilitian, sistem pengumpulan sampah, sistem pengumpulan sampah dan upaya pengelolaan sampah. Lokasi penelitian di Jl. Pulang Pisau. Objek penelitian adalah pengelolaan sampah. Sumber data berupa data primer dan data sekunder. Teknik pengumpulan data dilakukan dengan mengamati langsung petugas sampah lapangan. Analisis data berdasarkan metode aritmatik. Untuk menghitung proyeksi jumlah penduduk Pulang Pisau tahun 2013-2020 menggunakan metode aritmatik yang dianggap lebih efesien karena menghasilkan standar deviasi terkecil. Bertambahnya jumlah penduduk sangat mempengaruhi jumlah sampah yang hasilkan setiap tahun. Berdasarkan Standar Departemen Kesehatan Republik Indonesia volume sampah per jiwa penduduk Indonesia adalah 0,0025 $\mathrm{m}^{3} / \mathrm{jiwa} /$ hari. Berdasarkan hasil proyeksi pertumbuhan penduduk, jumlah penduduk Pulang Pisau pada tahun 2020 yaitu 128.279 dengan volume sampah $320 \mathrm{~m} / \mathrm{hari}$, sedangkan Pemerintah Kabupaten Pulang Pisau hanya mampu mengangkut sampah sebesar $18 \mathrm{~m}^{3} /$ hari. Sedikitnya Tempat Penampungan sementara (TPS) di Kota Pulang Pisau membuat sampah-sampah banyak yang masih berserakan dijalan untuk itu Pemkab Pulang Pisau harus menambah jumlah TPS, serta menambah jumlah dump truck agar penanganan sampah di kota Pulang Pisau berjalan dengan lancar dan tidak ada lagi sampah yang berserakan. Pada Tempat Pembuangan Akhir TPA perlu adanya petugas yang mengawasi TPA tersebut sehingga para pemulung tidak menghambur sampah di TPA.
\end{abstract}

Kata kunci: sampah, tempat pembuangan akhir (TPA), tempat penampungan, sementara (TPS)

\section{PENDAHULUAN}

Peningkatan jumlah pada pertumbuhan penduduk yang semakin tinggi serta pengembangan wilayah perkotaan akan menyebabkan manusia cenderung merusak lingkungan demi mempertahankan hidupnya.
Masalah ini dirasakan di negara-negara berkembang yang padat penduduknya, sehingga masalah yang timbul tersebut adalah akibat dari peningkatan aktifitas penduduk, industri dan lainya. Masalah yang sering muncul adalah mengenai kebersihan 
lingkungan, yang berkaitan dengan sampah. Sampah dalam sehari-harinya dikenal sebagai bahan, zat-zat atau benda-benda yang sudah tidak terpakai lagi, baik berupa sampah yang berasal dari rumah tangga, pasar, sampah kantor industri sebagai proses industri. Persoalan yang melatar-belakangi masalah sampah.

Sampah yang dibuang dan ditumpuk begitu saja di atas lahan terbuka dan tidak sempat terangkut. Di depan gang atau dipinggir jalan raya bahkan pada Tempat Pembuangan Sampah (TPS) sering terlihat tumpukan sampah yang belum terangkut atau berserakan di luar TPS, sehingga menyebabkan rendahnya nilai estetika lingkungan di sekitar tempat tersebut. Alat angkut yang dioperasionalkan tidak berjalan dengan optimal. Pengaturan jadwal operasional pengangkutan sampah belum maksimal. Tujuan penelitian ini adalah untuk mengetahui bagaimana cara menangani masalah sampah berhubungan dengan manajemen pengelolaan sampah (pengumpulan dan pengangkutan sampah) pada saat ini dan usulan penyempurnaannya.

\section{METODE PENELITIAN Objek Penelitian}

Sebagai objek penelitian, dibatasi hanya pada hal-hal yang berhubungan dengan penanganan sampah dengan tidak mengabaikan sarana pendukungnya seperti:

a. Sarana dan prasarana yang tersedia, yaitu tempat penampungan sementara, sapu, sekop, garuk, dan gerobak sampah

b. Jumlah personil/tenaga kerja

\section{Lokasi Penelitian}

Lokasi penelitian diwilayah Kota Pulang Pisau, kecamatan Kahayan Hilir.

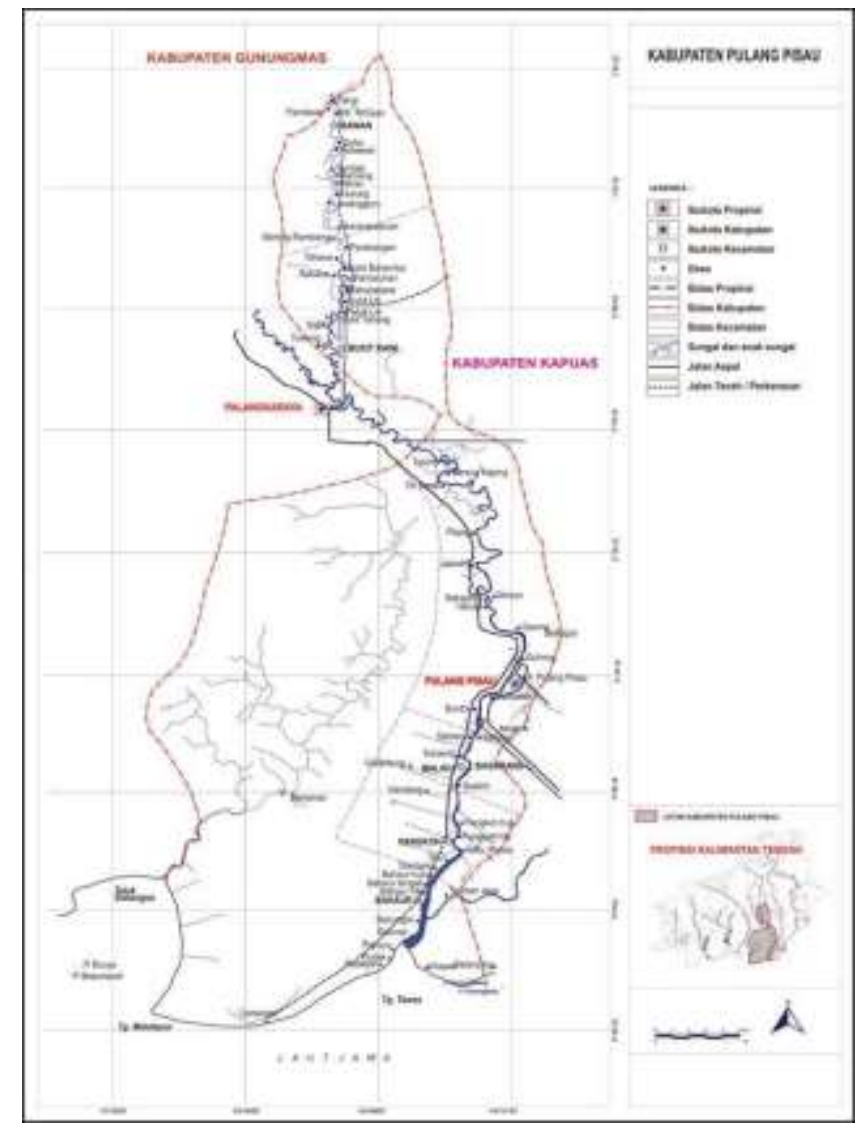

Gambar 1. Peta Lokasi Penelitian

\section{Pengumpulan Data}

Data primer atau data utama diperoleh dari penelitian langsung di lapangan seperti volume sampah, jumlah TPS (Tempat Pembuangan Sementara) dan lokasi TPA (Tempat Pembuangan Akhir). Data sekunder 
atau data kedua diperoleh dari Dinas Pekerja Umum Bidang Pertamanan dan Kebersihan Kabupaten Pulang Pisau dan studi literatur.

\section{Data Penelitian}

Dalam pelaksanaan penelitian, data dikumpulkan dengan mengamati langsung di lapangan. Adapun data yang dikumpulkan meliputi :

a. Data yang hubungannya dengan sampah yaitu Volume sampah 20

b. Data yang ada hubungannya dengan sistem pengumpulan sampah yaitu Jumlah dan volume TPS

c. Data yang ada hubungannya dengan sistem pengangkutan yaitu frekuensi pengangkutan sampah dan jumlah tenaga yang dipekerjakan

\section{Tahap Penelitian}

Secara garis besar, tahap-tahap yabg ditempuh dalam penelitian ini adalah :

a. Tahap Persiapan

Kegiatan yang dilaksanakan dalam tahap persiapan adalah menyusun jadwal penelitian dan menghubungi pejabat yang berwenang dalam penanganan sampah

b. Tahap Pelaksanaan

Tahap ini meliputi mengamati kegiatan petugas sampah mulai dari pengumpulan sampah di TPS sampai pengangkutan sampah ke TPA dan mengamati kegiatan penanganan sampah di TPA.

\section{Tahap Analisis Data}

Data tentang volume sampah dapat digunakan untuk mengetahui volume sampah yang dihasilkan oleh masyarakat Kota Pulang Pisau. Data tentang peralatan dapat dipergunakan untuk mengetahui jumlah alat angkut yang dioperasionalkan di tiap-tiap TPS. Data yang diperoleh dari hasil penelitian maupun data literatur dianalisis berdasarkan metode statistik deskriptif yang merupakan urutan pemecahan masalah dan uraian peralatan guna menghubungkan berbagai data sehingga dihasilkan kesimpulan yang jelas.

\section{HASIL DAN PEMBAHASAN \\ Hasil Penelitian \\ Deskripsi Objek Penelitian}

Pengelolaan sampah yang dikelola oleh Pemerintah Pulang Pisau pada saat ini masih belum dapat terlayani penuh. Jumlah sampah yang terangkut hanya beberapa persen saja dari jumlah produksi sampah total tiap harinya. Sisa sampah yang tidak terlayani biasanya dikelola sendiri oleh masyarakat, misalnya dengan menimbun, membakar, atau di daur ulang kembali.

\section{a. Pengangkutan}

Pengangkutan disini adalah kegiatan pengangkutan sampah dari TPS ke TPA. Para petugas kebersihan dengan menggunakan armada truk mulai mengambil sampah dari TPS di dalam kota-kota pukul 04.00 WIB. Mereka berkeliling untuk mengambil sampah di TPS-TPS yang tersebar di pinggir jalan protokol kota Pulang Pisau sesuai rit yang telah ditentukan. Setelah truk penuh dengan sampah kemudian diangkut ke TPA, kemudian mereka kembali ke dalam kota untuk mengambil sampah di TPS-TPS yang belum terangkut .Dalam sehari untuk mengangkut sampah ini hanya sekali pengangkutan sampah yaitumulai dari jam 04.00 - 08.00 WIB, dan menggunakan satu truk. Truk tersebut dapat mengangkut sampah 3 rite/hari. Kapasitas bucket truk rata-rata $6 \mathrm{~m}^{3}$.

\section{b. Pembuangan Akhir}

Tahap ini merupakan proses akhir dari sistem pembuangan sampah. Pembuangan sampah ilakukan langsung ke TPA yang letaknya di Desa Gohong. Luas TPA $75.230 \mathrm{~m}^{2}$, dengan usia efektif TPA sekitar 10 tahun. Sistem penanganan sampah di TPA Pulang Pisau seharusnya menggunakan sistem teoritis controlled landfill. Dimana sampah yang datang hari itu langsung dimasukkan ke kolam sampah yang telah dikeruk oleh 
excavator, setelah penuh ditutup dengan cover soil. Sampah yang datang pada hari itu tidak dicampur dengan sampah hari berikutnya, dikarenakan proses membusuknya akan berbeda-beda. Sedangkan penanganan sampah yang ada saat ini menggunakan sistem open dumping. Dimana sampah yang datang pada hari itu langsung ditumpuk/dibuang sembarangan, suatu cara primif tanpa pengelolaan lebih lanjut, adapun di TPA banyak pemulung yang dibiarkan bebas untuk memulung sehingga sampah berserakan tak beratur diluar TPA dan tercampur dengan sampah yang telah membusuk. Tidak heran bau sampah menyebar, lalat berterbangan dan rawan api. Sistem ini disebabkan Pemerintah tidak memperhatikan dampak lingkungan yang terjadi di TPA.

\section{c. Tempat Penampungan Sementara (TPS)}

Sampah-sampah yang berasal dari rumah tangga, kantor, pasar, sekolah dan sebagainya dikumpulkan masyarakat dan akhirnya dibuang ke tempat penampungan sementara yang tersebar di berbagai wilayah kecamatan dalam kota Pulang Pisau. Tempat penampungan sementara biasanya terbuat dari beton pasangan batu bata atau besi plat berbentuk persegi dengan ukuran panjang $3 \mathrm{~m}$, lebar $2 \mathrm{~m}$ dan tinggi $1 \mathrm{~m}$. Sedangkan tempat penampungan sementara (TPS) container berukuran $2 \times 3 \mathrm{~m}$, dengan ukuran seperti ini biasanya tidak mampu menampung sampah sehingga banyak sampah berserakan di sekitar TPS. Untuk dapat mengetahui lokasi TPS yangtersebar pada satu kecamatan dalam kota Pulang Pisau ini dapat di lihat pada tabel di bawah ini :
Tabel.1 Pelayanan pengangkutan sampah Wilayah :

\begin{tabular}{clc}
\hline No. & \multicolumn{1}{c}{ Nama Jalan } & Jumlah TPS (buah) \\
\hline 1 & Tinggang Menteng & 3 \\
2 & Pananjung Tarung & 2 \\
3 & Rai II & 1 \\
4 & W.A.D Duha & 1 \\
5 & Lintas & 1 \\
6 & Bereng & 1 \\
& Jumlah & 9 \\
\hline
\end{tabular}

Sumber : Dinas Pekerjaan Umum Kabupaten Pulang Pisau

\section{d. Volume Sampah}

Banyaknya produksi sampah yang dihasilkan oleh penduduk setiap harinya dapat dihitung berdasarkan jumlah penduduk, sesuai dengan SNI 03-32421994. Dan berdasarkan standar departemen Kesehatan Repulik Indonesia volume sampah per jiwa penduduk Indonesia adalah $0,0025 \mathrm{~m}^{3} / \mathrm{jiwa} / \mathrm{hari}$.

\section{Pembahasan \\ Proyeksi Jumlah Penduduk}

Dalam hal ini kita mencoba menghitung volume sampah dengan memproyeksikan jumlah penduduk kota Pulang Pisau pada tahun 2020. Dalam memproyeksikan jumlah penduduk kita menggunakan beberapa metode aritmatik yaitu :

Rumus yang digunakan pada metode aritmatik yaitu :

$\mathrm{Pn}=\mathrm{Po}+\mathrm{x} \mathrm{n}$

Keterangan :

$\mathrm{Pn}=$ Jumlah penduduk $\mathrm{n}$ tahun akan dating

Po $=$ Jumlah penduduk pada akhir tahun data

$\mathrm{Pt}=$ Jumlah penduduk pada awal tahun data

$\mathrm{n}=$ Jangka waktu proyeksi

$\mathrm{t}=$ jangka waktu tahun data

Tabel 2 Data Penduduk Pulang Pisau

\begin{tabular}{cc}
\hline Tahun & Jumlah Penduduk (jiwa) \\
\hline 2005 & 116.746 \\
2006 & 117.609863 \\
2007 & 117.889280 \\
2008 & 118.425536 \\
\hline
\end{tabular}




\begin{tabular}{cc}
\hline 2009 & 118.980555 \\
2010 & 119.9831 .003 \\
2011 & 122.0732 .090 \\
2012 & 122.511438 \\
2013 & 123.232721 \\
2014 & 123.953721 \\
Jumlah & 7.207 \\
\hline
\end{tabular}

Sumber: BPS Kabupaten Pulang Pisau

$$
\begin{aligned}
& \mathrm{Po}-\mathrm{Pt} \\
& \mathrm{Pn}=\mathrm{Po}+\mathrm{x} \mathrm{n} \\
& \mathrm{P} 2013=123.953+\mathrm{x} 1=124.674 \text { Jiwa }
\end{aligned}
$$

Hasil perhitungan untuk selanjutnya dapat dilihat pada Tabel 3.

Tabel 3 Proyeksi Jumlah Penduduk Pulang Pisau Tahun 2014 - 2020 dengan Metode aritmatik

\begin{tabular}{ll}
\hline 2015 & 124.674 \\
2015 & 125.395 \\
2016 & 126.116 \\
2017 & 126.116 \\
2018 & 126.837 \\
2019 & 127.558 \\
2020 & 128.279 \\
\hline
\end{tabular}

Sumber : Hasil Analisis

\section{Proyeksi Volume Sampah}

\section{a. Proyeksi Volume Sampah Tahun 2014}

Berdasarkan data yang diperoleh dari pemkab pulang pisau, maka produksi sampah untuk pulang pisau dapat diperkirakan per hari untuk tahun 2014 sebesar :

Total volume sampah

$\mathrm{Vt}=123.953$ jiwa $\times 0,0025 \mathrm{~m}^{3} / \mathrm{jiwa} /$ hari

$=309,882 \mathrm{~m}^{3} / \mathrm{hari}$

Total volume rata-rata per TPS diperkirakan :

V rata-rata $=$ Vol. Sampah Puang Pisau

Po - Pt 7.207

$\Sigma$ TPS yang ada $=309,882 \mathrm{~m}^{3} /$ hari $=34,43$ $\mathrm{m}^{3} /$ hari

Sarana pemindahan/pengangkutan yang ada sekarang (2014) yaitu :

Jumlah truck 1unit kapasitas $6 \mathrm{~m}^{3}$ ( 3 rite/truck)

Total volume sampah yang mampu dipindahkan/diangkut :
Truck $1 \times 6 \times 3$ rite $=18 \mathrm{~m}^{3} /$ hari

Volume/timbulan sampah yang tersisa/tidak mampu diangkut oleh Pemkab : $309,882 \mathrm{~m}^{3} /$ hari $-18 \mathrm{~m}^{3} /$ hari $=291,822$ $\mathrm{m}^{3} /$ hari

Persentase sampah penduduk yang mampu diatasi oleh Pemkab untuk tahun 2014 sebesar : $x 100 \%=5,6 \%$

\section{b. Proyeksi Volume Sampah Tahun 2020}

Berdasarkan proyeksi jumlah penduduk di kota Pulang Pisau, maka produksi sampah untuk kota Pulang Pisau diperkirakan per hari untuk tahun 2020 sebesar :

Total volume sampah

$\mathrm{Vt}=128.279$ jiwa $\times 0,0025 \mathrm{~m}^{3} /$ jiwa/hari $=$ $320,70 \mathrm{~m}^{3} / \mathrm{hari}$

Total volume rata-rata per TPS diperkirakan :

V rata-rata $=$ Vol. Sampah Puang Pisau 18 $\mathrm{m}^{3} /$ hari $=309,882 \mathrm{~m}^{3} /$ hari

$\Sigma$ TPS yang ada

$=320,70 \mathrm{~m}^{3} / \mathrm{hari}=$

$=35,64 \mathrm{~m}^{3} /$ hari

Sarana pemindahan/pengangkutan yang ada sekarang (2014) yaitu :

Jumlah truck 1unit kapasitas $6 \mathrm{~m}^{3}$ ( 3 rite/truck)

Total volume sampah yang mampu dipindahkan/diangkut :

Truck $1 \times 6 \times 3$ rite $=18 \mathrm{~m}^{3} /$ hari

Volume/timbulan sampah yang tersisa/tidak mampu diangkut oleh Pemkab

$320,70 \mathrm{~m}^{3} /$ hari $-18 \mathrm{~m}^{3} /$ hari $=302.7 \mathrm{~m}^{3} /$ hari Persentase sampah penduduk yang mampu diatasi oleh Pemkab untuk tahun

2020 sebesar :

x $100 \%=5,6 \%$

Jadi hanya 5,6 \% sampah penduduk Pulang Pisau yang mampu diatasi oleh Pemkab Pulang Pisau setiap harinya. Padahal seharusnya Pemda harus mampu mengatasi sampah kota sebesar $80 \%$.

Sedangkan tempat penampungan sementara (TPS), idealnya di Pulang Pisau1 TPS hanya 500 orang. TPS yang tersedia 9 TPS jadi untuk tahun 2020 Pulang Pisau kekurangan TPS sebesar $128.279: 500=256$ TPS, Kekurangan $=$ 
$256-9=247$ unit TPS $=18 \mathrm{~m}^{3} /$ hari $=320,70 \mathrm{~m}^{3} /$ hari

\section{c. Truck Pengangkutan Sampah}

Menurut data investaris, jumlah armada pengangkutan yang dimiliki Dinas Pekerjaan Umum Bidang Pertamanan dan Kebersihan Kabupaten Pulang Pisau adalah sebagai berikut :

Dump Truck sebanyak 1 unit yaitu :

\section{KH 9005 JW Tahun 1997}

Kemampuan armada angkut untuk tahun 2020 harus mampu mengangkut sampah sebanyak 320,70 $\mathrm{m}^{3} /$ hari. Pengangkutan sampah dalam kota dilayani oleh 1 unit dump truck dengan kapasitas bucket $6 \mathrm{~m}^{3}$.

a. Produksi Dump Truck $=\mathrm{n} \times$ kapasitas/rit $=1 \times 6$

$=6 \mathrm{~m}^{3} / \mathrm{rit}$

b. Frekuensi angkut $=$ Jumlah Sampah

Prod. Truck $=320,706=53,45$ rit

Setiap dump truck mengangkut sampah rata-rata 53,45 rit/hari.

Melihat kondisi alat angkut yang tidak efesien dengan frekuensi 53,45 rit/hari akan memakan waktu lama, juga para pekerja pengangkut sampah akan mengalami kelelahan.

Sedangkan frekuensi layanan pengangkutan sampah ke TPA yang dijadwalkan oleh Dinas Pekerjaan Umum Bidang Pertamanan dan Kebersihan Kabupaten Pulang Pisau 3 rit/hari, hal ini tidak sesuai dengan frekuensi ideal yang disarankan yaitu maksimum 4 rit/hari. Maka produksi truck dalam kota/hari berdasarkan jadwal Dinas Pekerjaan Umum Bidang

Pertamanan dan Kebersihan Kabupaten Pulang Pisau sebanyak 3 rit/hari.

Dump truck $=\mathrm{n} \times$ Kapasitas $\times$ Frekuensi

$=1 \times 6 \times 3$

$=18 \mathrm{~m}^{3} /$ hari

Total sampah yang bisa terangkut tiap hari dengan frekuensi angkut 3 rit/hari $=18$ $\mathrm{m}^{3} /$ hari Dengan memperhitungkan faktor penyusutan dalam pengangkutan $0,8 \%$ maka sampah yang masuk ke TPA per hari sebanyak : $=\mathrm{x} 99,2 \%=178,56 \mathrm{~m}^{3} / \mathrm{hari}$

Sisa sampah yang tidak terangkut oleh Pemkab sebesar $302.7 \mathrm{~m}^{3} /$ hari.

Untuk mengatasi sisa tersebbut perlu adanya penambahan truck :

$\mathrm{N}$ = banyak sisa sampah

Produksi truck

$\mathrm{N}=302.7$

$6=50$ unit truck

Dengan 3 rit/hari diperlukan penambahan armada truck sebanyak 50 unit, agar dapat mengangkut sampah kota Pulang Pisau pada tahun 2020 .

\section{KESIMPULAN}

Dari uraian-uraian yang telah disajikan, maka dapat diambil kesimpulan sebagai berikut :

a. Produksi sampah untuk Pulang Pisau diperkirakan per hari untuk tahun 2020 sebesar 320,70 $\mathrm{m}^{3} /$ hari, dengan jumlah armada pengangkut sampah dump truck 1 unit untuk saat ini tidak mampu mengangkut sampah secara keseluruhan. Dengan jumlah armada yang terbatas Pemkab Pulang Pisau hanya mampu mengangkut sampah 18 $\mathrm{m}^{3} /$ hari, sedangkan yang tidak

mampu diangkut sebesar $302.7 \mathrm{~m}^{3} /$ hari, dengan demikian diperlukan penambahan armada sebanyak 50 dump truck.

b. Untuk mengatasi masalah sampah di Pulang Pisau diperlukan suatu jadwal kinerja armada yang maksimal. Mengacu pada jumlah ritase 3 rit/hari,belum dapat mengatasi permasalahan tersebut. Tidak menutup kemungkinan sampah yang ada tidak terangkut keseluruhan, tetapi bila mengacu pada jumlah dan waktu yang dibutuhkan dalam mengangkut sampah dari 1 TPS, memungkinkan kinerja alat yang ada bekerja dengan maksimal sehingga sampah-sampah dapat terangkut semua setiap hari.

c. Persentase sarana untuk mengatasi volume sampah kota Pulang Pisau untuk tahun 2020 sebesar 5,6 \% idealnya, Pemkab Pulang Pisau harus mampu mengatasi sampah kota sebesar $80 \%$.Sedangkan tempat penampungan sementara (TPS), idealnya di Pulang Pisau 1 TPS hanya 500 orang. TPS yang tersedia 9 unit TPS jadi Pemkab Pulang Pisau masih kekurangan TPS sebanyak 247 TPS. 


\section{SARAN}

1. Pemerintah Kabupaten Pulang Pisau supaya dapat mengacu pada jumlah waktu yang dibutuhkan setiap armada dalam satu hari agar tidak ada alat angkut yang beroperasi melebihi jam kerjanya.

2. Pemerintah Kabupaten Pulang Pisau dalam pemilihan daerah/lokasi TPA hendaknya selalu memperhatikan dampak lingkungan yang terjadi di TPA.

3. Untuk kedepannya sangat diperlukan adanya alat berat excavator dan buldozer dilokasi TPA dan untuk membenahi aspek SDM kedepan seluruh tenaga yang dialukasikan untuk TPA, benar-benar orang yang bekerja penuh di TPA.

4. Banyak mengadakan penyuluhan kemasrakat, perkantoran, pertokoan, perusahaan, agar sebelum membuang sampah dapat memilahnya lagi, yang mana masih bisa dipakai atau didaur ulang, yang menghasilkan uang untuk membantu pendapat rumah tangga.

\section{DAFTAR PUSTAKA}

Badan Pusat Statistik Kabupaten Pulang Pisau. 2010. Data Penduduk Pulang Pisau, Pulang Pisau.

Dinas Pekerja Umum Kabupaten Pulang Pisau. 2014. Final Report Sektor Persampahan Kabupaten Pulang Pisau, Pulang Pisau.

Harry, Apriadji Wied., 1998. Memproses Sampah. PT . Penerbit Swadaya, Bogor.

Lembaga Penyelidikan Masalah Bangunan, Bandung. 1994. Tata Cara Pengelolaan Sampah di Indonesia. SNI. 03-3242-1994. 